\title{
Synthesis of Polyamide-6/Montmorillonite Nanocomposites by Direct In-situ Polymerization Catalysed by Exchanged Clay
}

\author{
DJAMAL EDDINE KHERROUB ${ }^{1 *}$, MOHAMMED BELBACHIR ${ }^{1}$, \\ SAAD LAMOURI ${ }^{2}$, LARBI BOUHADJAR ${ }^{1}$ and KARIM CHIKH ${ }^{1}$
}

\author{
'Laboratoire de chimie des polymères, Département de Chimie, Faculté des Sciences, \\ Université d'Oran, BP 1524 El'Menouer Oran 31000, Algeria. \\ ${ }^{2}$ Laboratoire de Chimie Macromoléculaire, Ecole Militaire Polytechnique (EMP), \\ Bordj El Bahri, 16111 Alger, Algeria. \\ E-mail: djamaleddine.kherroub@yahoo.com \\ http://dx.doi.org/10.13005/ojc/290419
}

(Received: September 25, 2013; Accepted: November 13, 2013)

\begin{abstract}
The purpose of this study was to obtain polyamide- 6 nanocomposites with national organically modified clay (termed 12-montmorillonite). The formation of polyamide- 6 was confirmed by infrared spectroscopy (IR), the prepared nanocomposites were characterized by X-ray diffraction (XRD), transmission electron microscopy (TEM) and thermogravimetric analysis (TGA). The evolution of mechanical properties was also studied. The obtained results confirm the intercalation of molecules of salt in the clay layers, and a good interaction with the polymer, showing the formation of intercalated and/or partially exfoliated structures. The nanocomposites showed higher thermal stability compared to pure polymer, and the mechanical properties presented interesting and promising results.
\end{abstract}

Key words: Maghnite, 12-Montmorillonite; Nanocomposites; Polyamide-6; Exfoliation.

\section{INTRODUCTION}

During the last decade, polymer/clay nanocomposites have received increasing attention from scientists and industrial researchers because they generally exhibit greatly improved mechanical, thermal, barrier, and flame-retardant properties at low clay content in comparison with unfilled polymers or more conventional microcomposites ${ }^{1,10}$.

Polyamide-6 (PA6) is an important group of the thermoplastic with excellent solvent resistance and good processability. However, PA6 exhibits a relatively rapid crystallization rate, which has some drawbacks such as high mold shrinkage and dimensional instability. In order to control the crystallization rate and the crystallinity, and then achieve the desired morphology and properties, a great deal of effort has been made to study the crystallization kinetics corresponding to the change of the performed properties ${ }^{11}$. Since the first studies on polyamide-6/montmorillonite nanocomposites (PA6/MMT) obtained via in situ intercalative polymerization $^{12}$, a wide range of polymers have 
been studied as hosting matrices for nanoclays resulting in a rich literature ${ }^{13-18}$. Nevertheless, PA6 remains a particularly successful choice for nanoclay composites and a lot of research has been devoted to the use of direct melt compounding of PA6 and, usually, smectite clays (i.e., MMT) as a more viable and industrially attractive preparation method than in situ polymerization ${ }^{19,20}$.

The most frequently employed layered silicates, such as montmorillonite, are smectitetype and belong to the family of $2: 1$ phyllosilicates. Their crystalline structure is composed of stacked layers made of two silica tetrahedrons fused to an edge-shared octahedral sheet of aluminium or magnesium hydroxide. Pristine clays are hydrophilic and thus immiscible with most polymers, due to alkali cations residing in the interlayer to counterbalance the negative charge generated by isomorphic substitutions within the silicate sheets. However, the polymer-clay compatibility can be improved via ion-exchange reactions with organic surfactants, including mainly alkylammonium cations ${ }^{21,22}$.

Therefore, the purpose of this study was to obtain polyamide- 6 nanocomposites with national organically modified clay. The novelty of this work is the fact that we use clay of our region, which constitutes low costs and has excellent properties.

\section{EXPERIMENTAL}

\section{Materials}

E-caprolactam (grade 99\%) and 12aminolauric acid were used as purchased from Aldrich chemical. Raw-Maghnite: Algerian montmorillonite clay which has been used as catalyst is supplied by a local company (ENOF Maghnia (Western of Algeria)). Its chemical composition is given in (Table 1).

\section{Methodology \\ Preparation of Maghnite-Na}

Maghnite-Na was prepared according to the process reported in our previous study [23,24]. Raw-Maghnite $(20 \mathrm{~g})$ was crushed for 20 min using a prolabo ceramic balls grinder. It was then dried for $2 \mathrm{~h}$ at $105^{\circ} \mathrm{C}$. The Maghnite was placed in an Erlenmeyer flask together with $500 \mathrm{ml}$ of $1 \mathrm{M} \mathrm{NaCl}$. The Maghnite/water mixture was stirred using a magnetic stirrer until saturation was achieved over 3 $\mathrm{h}$ at room temperature, the mineral was then washed with distilled water to became $\mathrm{Cl}^{-}$free and then dried at $105^{\circ} \mathrm{C}$.

\section{Preparation of 12-Montmorillonite}

Natural Na-montmorillonite is hydrophylic and not compatible with most organic molecules. The sodium cation in the interlayer space of montmorillonite can be exchanged with organic cations to yield organophilic montmorillonite. For the present purpose, polymerization in the interlayer space, ammonium cations of É-amino acid were chosen as cations since the $-\mathrm{COOH}$ group of them catalyzes the ring opening polymerization of $\mu$-caprolactam. In a $1000 \mathrm{ml}$ beaker were placed 24 mmol of 12-aminolauric acid, $2.4 \mathrm{ml}$ of concentrated hydrochloric acid and $200 \mathrm{ml}$ of water at $80^{\circ} \mathrm{C}$. The solution of the 12-aminolauric acid was added to a dispersion composed of $10 \mathrm{~g}$ of montmorillonite- $\mathrm{Na}$ and $1000 \mathrm{ml}$ of hot water, and then this mixture was stirred vigorously for $10 \mathrm{~min}$, giving a white precipitate. The product was filtered, washed with hot water, and freeze-dried. In this paper, we call the cation exchanged montmorillonites '12-montmorillonite', where $n$ is the carbon number of the 12-aminolauric acid [25]. The basal spacings (interlayer distance) of the samples were obtained from the peak position of the XRD pattern.

\section{Preparation of the nanocomposites}

In a vessel, $113 \mathrm{~g}$ of $\mu$-caprolactam and 1 , 3, 5 and $10 \mathrm{wt} \%$ of 12 -montmorillonite were placed. The mixture was heated at $100{ }^{\circ} \mathrm{C}$ for $30 \mathrm{~min}$. Then, it was heated at $250{ }^{\circ} \mathrm{C}$ for $48 \mathrm{~h}$, yielding a polymeric product. After cooling, the product was mechanically crushed. The fine particles were washed with 2:1 of water at $80^{\circ} \mathrm{C}$ for $1 \mathrm{~h}$ [25], the nanocomposites will then be denoted as PANC1, PANC3, PANC5 and PANC10 according to their containing clay.

\section{Characterization \\ Infrared spectroscopy (IR)}

IR analysis of virgin polyamide-6 (without clay) was carried out using the PerkinElmer Spectrum Two FT-IR with UATR sampling accessory.

\section{X-Ray Diffraction (XRD)}

X-ray diffraction analysis (XRD) was carried out at room temperature on a Bruker D8 Advance X-Ray diffractometer (40 kV, $30 \mathrm{~mA})$ using CuK $\alpha$ 
radiation $(\lambda=0.154 \mathrm{~nm})$ at the rate of $2^{\circ} \mathrm{min}^{\prime 1}$ in the 2 , range of $2.0^{\prime \prime} 80^{\circ}$.

\section{Transmission Electron Microscope (TEM)}

The phase morphologies of the nanocomposites were observed by transmission electron microscope (TEM), Philips CM 120, operating at an acceleration voltage of $120 \mathrm{kV}$. Samples were cryogenically.

\section{Thermogravimetry (TG)}

The thermogravimetry (TG) technique was also used, by means of TGA 51 Shimadzu equipment, operating at a heating rate of $10.0^{\circ} \mathrm{C}$ $\mathrm{min}^{-1}$, from room temperature up to $900{ }^{\circ} \mathrm{C}$ under an air atmosphere with a flow rate of $50 \mathrm{~mL} \mathrm{~min}^{-1}$. The sample mass was $5.0 \pm 0.5 \mathrm{mg}$. The TG curves were analyzed with the aid of the TASYS software from Shimadzu.

\section{Mechanical Properties}

Tensile tests were conducted using a LLoyd LR/10KN Universal Machine at room temperature and crosshead speed of $50 \mathrm{~mm} / \mathrm{min}$ for the determination of tensile modulus, yield strength and elongation at yield measurements, according to the standard ASTM D638. Izod impact tests were carried out on notched specimens at room temperature using a Ceast Resil 5.5 equipment, according to the standard ASTM D256. Typically, five or more samples were used for each determination.

\section{RESULTS AND DISCUSSION}

\section{Infrared spectroscopy (IR)}

The IR measurements of virgin PA6 are in a good agreement with polyamide- 6 structure (Fig. 1). It is shown that the broad band at 3301.81 $\mathrm{cm}^{-1}$, usually assigned to the $\mathrm{N}-\mathrm{H}$ bending vibration in primary amine. The two bands at 2930.31 and $2861.84 \mathrm{~cm}^{-1}$ are assigned to the $\mathrm{CH}$ stretching of the ethylene sequence ${ }^{26}$. Moreover, the absorbance at $1645.95 \mathrm{~cm}^{-1}$ related to $\mathrm{C}=\mathrm{O}$ amide I stretch and the combination absorbance of the $\mathrm{N}-\mathrm{H}$ and $\mathrm{C}-\mathrm{N}$ amide II stretch at $1551.45 \mathrm{~cm}^{-1}$ are clearly observed ${ }^{27}$. For the spectrum of PANC3, the same bands appear just the absorption of $\mathrm{N}-\mathrm{H}$ (appears at 3294.87 $\mathrm{cm}^{-1}$ ) and $\mathrm{C}=\mathrm{O}$ (appears at $1631.55 \mathrm{~cm}^{-1}$ ) show obvious displacement to lower frequency compared to neat PA6. In consideration of the fact that there are plentiful silanol groups on the surface of nanosilica, these results should indicate the existence of hydrogen bonds between PA6 and nano-silica ${ }^{28-30}$.

\section{X-Ray Diffraction (XRD)}

The basal spacings (interlayer distance) of the raw clay (MMT), clay treated with $\mathrm{NaCl}$ (MMT-Na), organophilic montmorillonite (12MMT) and their nanocomposites with PA6 were obtained from the peak position of the XRD pattern. The MMT shows the characteristic peak of the

\section{Table 1: Chemical composition of the Catalyst}

\begin{tabular}{ll}
\hline Species & $\%(w / w)$ \\
\hline $\mathrm{SiO}_{2}$ & 69.4 \\
$\mathrm{Al}_{2} \mathrm{O}_{3}$ & 14.7 \\
$\mathrm{Fe}_{2} \mathrm{O}_{3}$ & 1.2 \\
$\mathrm{MgO}$ & 1.1 \\
$\mathrm{CaO}$ & 0.3 \\
$\mathrm{Na}_{2} \mathrm{O}$ & 0.5 \\
$\mathrm{~K}_{2} \mathrm{O}$ & 0.8 \\
$\mathrm{TiO}_{2}$ & 0.2 \\
$\mathrm{AS}$ & 0.05 \\
$\mathrm{L.O} . \mathrm{I}$ & 11 \\
\hline
\end{tabular}

L.O.I: Loss on ignition at $900{ }^{\circ} \mathrm{C}$ in wt $\%$

Table 2: TGA results of PA6 and nanocomposites

\begin{tabular}{llllll}
\hline & \multirow{2}{*}{ PA6 } & \multicolumn{4}{c}{ Nanocomposites with various clay content (wt \%) } \\
& & $\mathbf{1} \%$ & $\mathbf{3} \%$ & $\mathbf{5} \%$ & $\mathbf{1 0} \%$ \\
\hline $\mathrm{T}_{10 \%}$ & 322.18 & 337.68 & 371.18 & 405.27 & 396.64 \\
$\mathrm{~T}_{50 \%}$ & 445.47 & 439.21 & 442.78 & 454.47 & 454.27 \\
$\mathrm{~T}_{90 \%}$ & 472.96 & 451.76 & 448.78 & 467.27 & 467.27 \\
Residue (wt\%) & 0.01 & 1.09 & 3.05 & 4.92 & 9.98 \\
\hline
\end{tabular}


Table 3: Mechanical properties of PA6 and its nanocomposites.

\begin{tabular}{lccc}
\hline Specimens & Tensile Modulus (GPa) & Yield Strength (MPa) & Elongation at Yield \\
\hline Pure PA6 & 1.08 & 64 & 45 \\
PANC1 & 1.88 & 82 & 5.3 \\
PANC3 & 2.00 & 103 & 5.8 \\
PANC5 & 1.34 & 98 & 5.1 \\
PANC10 & 1.11 & 75 & 4.7 \\
\hline
\end{tabular}

montmorillonite at $2 \theta=8.50$, corresponding to the interlayer distance ( $d_{001}$-spacing) of $10.39 \AA$. For the MMT-Na, the peak of the montmorillonite is found at $2 \theta=6.95$, corresponding to the interlayer distance $\left(d_{001}\right.$-spacing $)$ of $12.70 \AA$. The $d_{001}$ peak for the 12MMT clay was shifted to a lower region $(2 \theta=5.01)$, indicating the increase in $\mathrm{d}_{001}$-spacing $(=17.62 \AA)$ in the modified clay. An increase in $\mathrm{d}_{001}$-spacing for 17.6 $\AA$ was previously found by Katti et al. ${ }^{31}$, when the organic moiety replaced the intra-gallery $\mathrm{Na}^{+}$of MMT$\mathrm{Na}$, resulting 12-MMT. Our result unambiguously led us to assume the replacement of smaller $\mathrm{Na}^{+}$ions by bulky molecules of 12-aminolauric acid inside the clay galleries that resulted in the increase in the gallery height of the MMT layers during ion-exchange reaction (Fig. 2a).

Figure. $2 \mathrm{~b}$ shows the XRD analysis of different nanocomposites prepared (1, 3, 5 and 10 wt \%). The strong diffraction peak of the pristine clay (12-MMT) is not observed on the patterns of PANC1 and PANC3, that the clays are rather well exfoliated in the PA6 matrix at low filler contents. As the clay content increases, i.e. for PANC5 and PANC10, a diffraction peak at $2_{s}=2.80$ and 3.01 respectively, the clay layers are not exfoliated whereas they are intercalated by the polymer chains as suggested by the increase of the $d_{001}$ value.

\section{Transmission Electron Microscope (TEM)}

These observations let us presume that the fillers were mostly homogeneously dispersed within the PA6 matrix and TEM analysis was further used to study in detail the filler dispersion state. Whatever the loading, the inorganic layers are lying parallel to the film surface and they are mainly well dispersed in the polyamide matrix. The exfoliated structure of nanocomposites PA6/12-MMT of low clay content is fully confirmed. Figure. 3 shows that, With $3 \mathrm{wt} \%$ 12-MMT; individual clay platelets are randomly distributed in the PA6 matrix and confirm the exfoliated structure of the resulted nanocomposite. The morphological description obtained by TEM support the results obtained by XRD analysis.

\section{Thermogravimetry (TG)}

TGA and DTG curves obtained in a nitrogen atmosphere for the virgin PA6 and nanocomposites is shown in (Figure 4.a) and (Figure 4.b) respectively. It can be seen that the virgin PA6 and all its nanocomposites exhibit one-step weight loss mechanism. The temperatures at which 10 , 50 , and $90 \%$ weight loss occur as representative of thermal stability are listed in (Table 2). It is evident that the influence of clay on thermal stability of PA6 differs at different ranges of weight loss. At lower weight loss (10 and 50\%), the notable tendency of improved thermal stability of the nanocomposites with increasing clay content can be seen from Table 2. At present, the detailed mechanism of thermal stabilization of the filled PA6 systems is not clearly understood. According to Theng ${ }^{32}$ and Velde ${ }^{33}$, the interaction between the amide groups of PA6 molecules and the ionic groups at the clay surfaces probably suppresses thermal degradation of the composite matrix. However, it is interesting to find that thermal stability of nanocomposites is slightly inferior to the virgin PA6 when higher weight loss (90\%) is considered, the same results are obtained by Cai et al., ${ }^{34}$. Such results indicate that the introduction of clay might change the decomposition mechanism of PA6 under high temperature. However, it is clear that these results support largely the results obtained from RDX and MET.

\section{Mechanical Properties}

Table.3 shows yield strength, tensile modulus and elongation at yield of pure PA-6 and its nanocomposites. It was seen that the nanocomposites showed improved mechanical properties compared to pure polyamide, in the others words, the clay acted as a nucleating agent, increasing the stiffness of 


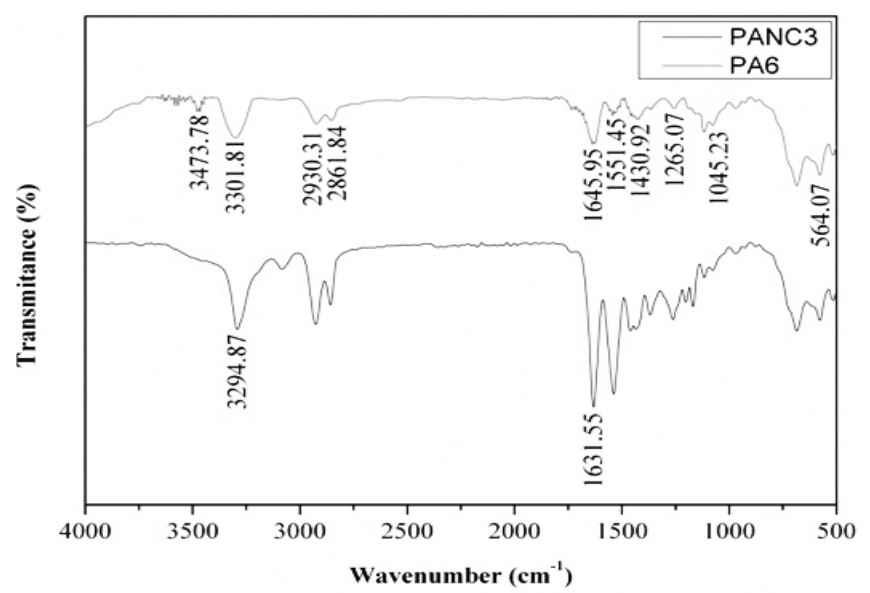

Fig. 1: FT-IR spectrum of virgin PA6 product of the reaction

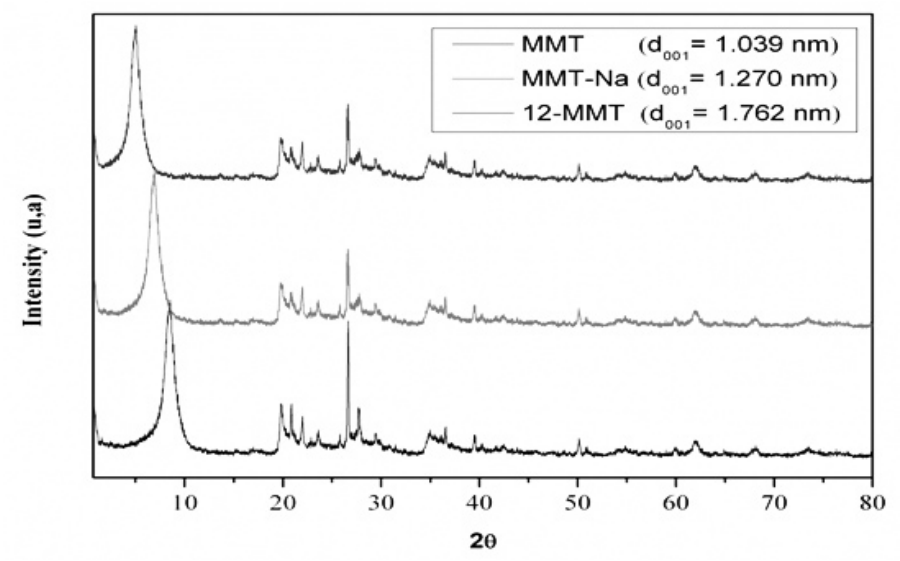

Fig. 2(a): XRD patterns of the clay without treatment (MMT), clay treated with $\mathrm{NaCl}$ (MMT-Na), and organophilic clay (12-MMT)

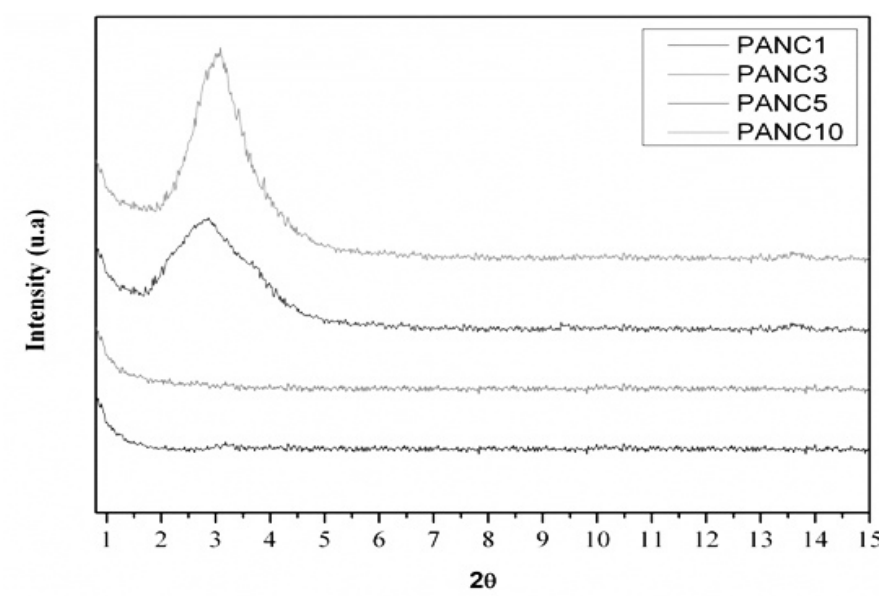

Fig. 2(b): XRD patterns of nanocomposites PA6/12-MMT 


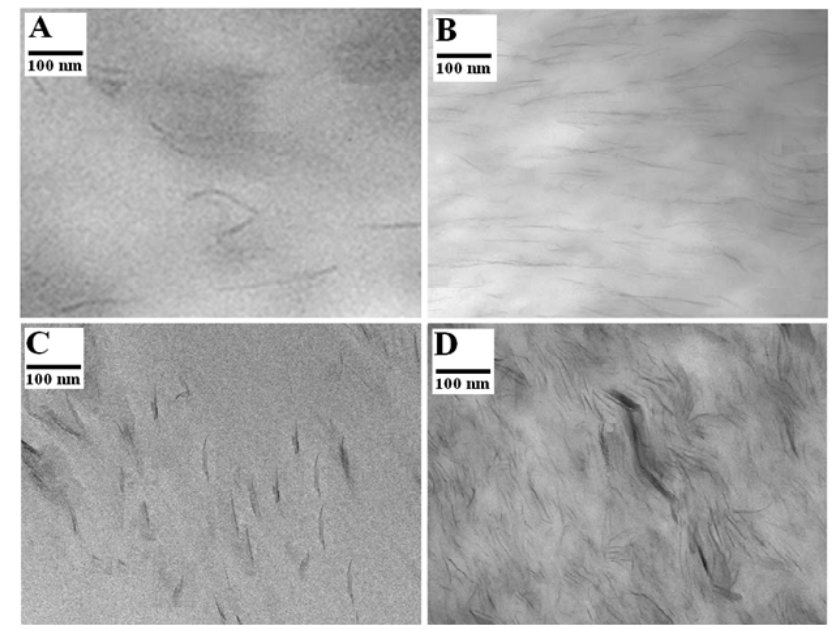

Fig. 3: TEM images of: (a) PANC1 (Exfoliated), (b) PANC3 (Exfoliated), (c) PANC5 (Intercalated) and (d) PANC10 (Immiscible).

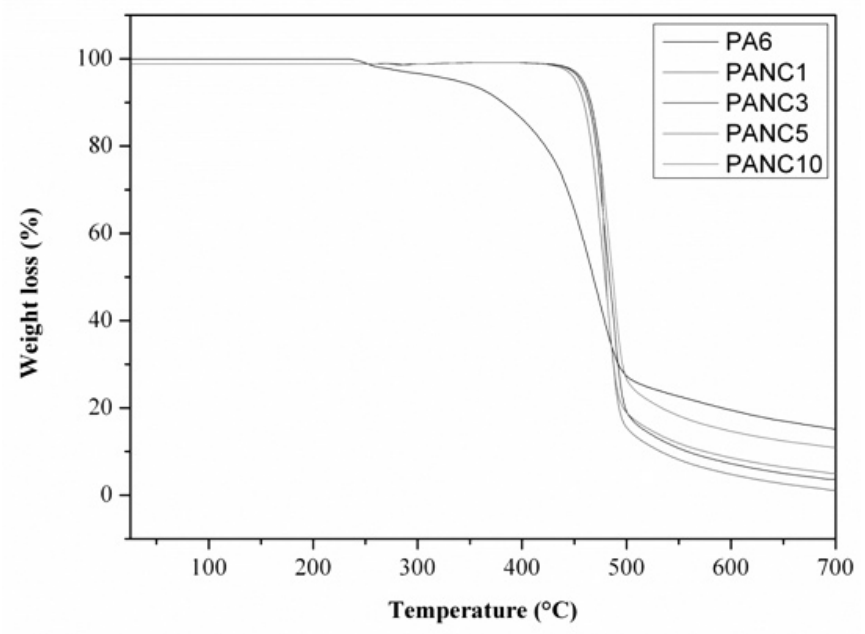

Fig. 4(a): TG curves of polyamide-6 and its nanocomposites

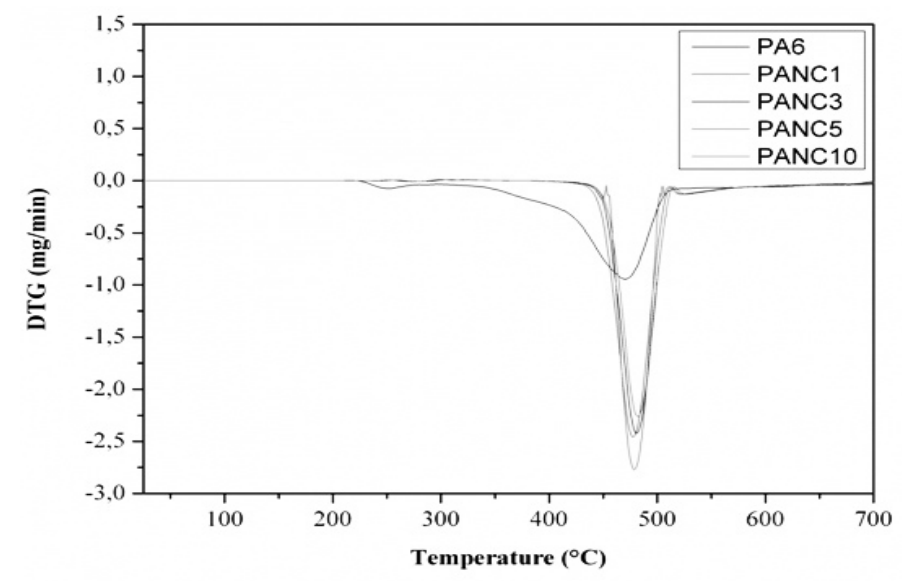

Fig. 4(b): DTG curves of polyamide-6 and its nanocomposites. 
the material. It was also observed that there was an increase in tensile modulus and yield strength for the systems of PA6/MMT in relation to pure PA6, this increase in tensile modulus and yield strength is maximum for PANC3, approximately $46 \%$ and $38 \%$ respectively in comparison the pure PA6. Although, it used only $3 \%$ of clay, an enhancement in mechanical properties was observed. Therefore, so the nanocomposites are exfoliated, that the mechanical properties are more improved.

\section{CONCLUSION}

The effect of organoclay (12-MMT) prepared and used with different ratios, in the properties of PA6/Algerian clay nanocomposites was studied. The results of XRD indicated that both nanocomposites prepared with $1 \%$ and $3 \%$ were exfoliated, but which prepared with $5 \%$ is intercalated among two basal planes of MMT, leading to an expansion of the interlayer spacing. Moreover, the nanocomposite prepared with $10 \%$ of clay is immiscible, almost no change of the interlayer spacing was observed. These results were confirmed by TEM. The results of thermogravimetry indicated that the nanocomposites showed largely higher thermal stability compared to pure polymer $\left(T<500{ }^{\circ} \mathrm{C}\right)$. This is attributed to interactions between the set of polymer chains and the organic compounds of modified clays. The reinforcing effect of clay in the polymer was confirmed by the increased rigidity of the system. In general, the data showed 12-amionolauric acid to be efficient in the organophilization of clay and suggested that the Algerian clay can be used as a nanoparticle in PA6 nanocomposites.

\section{REFERENCES}

1. T. J. Pinnavaia, G. W. Beall, Polymer-clay nanocomposites, Wiley Series in Polymer Science, Wiley, New York (2000).

2. M. Alexandre, Ph. Dubois, Mater. Sci. Eng. , 28: 1 (2000).

3. M. Biswas, S. S. Ray, Adv. Polym. Sci., 15: 167 (2000).

4. E. P. Giannelis, Adv. Mater. 8: 29 (1996).

5. Y. Kojima, A. Usuki, M. Kawasumi, A. Okada, T. Kurauchi, O. Kamigaito, J. Polym. Sci., Part A: Polym.Chem., 31: 983 (1993).

6. J. W. Gilman, Appl. Clay Sci. 15: 31 (1999).

7. K. E. Strawhecker, E. Manias, Chem. Mater., 12: 2943 (2000).

8. R. Krishnamoorti, R. A. Vaia, E. P. Giannelis, Chem. Mater. 8: 17281 (1996).

9. P. B. Messersmith, E. P. Giannelis, Chem. Mater. 5: 1064 (1993).

10. S. S. Ray, M. Okamoto, Prog. Polym. Sci. 28: 1539 (2003).

11. Liu, Y.; Yang, G. Non-isothermal crystallization kinetics of polyamide-6/graphite oxeide nanocompósitos. Thermochim. Acta, 500: 13-20 (2009).

12. Pinnavaia, T.J.; Beall, G.W. Polymer-Clay Nanocomposites; Wiley: New York, NY, USA, (2000).

13. Ray S.S.; Okamoto, M. Polymer-layered silicate nanocomposite: A review from preparation to processing. Prog. Polym. Sci., 28: 1539-1641 (2003).

14. Cho, J.W.; Paul, D.R. Nylon 6 nanocomposites by melt compounding. Polymer, 42: 10831094 (2001).

15. Liu, T.; Tjiu, W.C.; He, C.; Na, S.S.; Chung, T.S. A processing-induced clay dispersion and its effect on the structure and properties of polyamide 6. Polym. Int., 53: 392-399 (2004).

16. Bilotti, E.; Zhang, R.; Deng, H.; Quero, F.; Fischer, H.R.; Peijs, T. Sepiolite needle-like clay for PA6 nanocomposites: An alternative to layered silicates? Compos. Sci. Technol. 69: 2587-2595 (2009).

17. Kojima, Y.; Usuki, A.; Kawasumi, M.; Okada, A.; Fukushima, Y.; Kurauchi, T.; Kamigaito, $\mathrm{O}$. Mechanical properties of nylon-6-clay hybrid. J. Mater. Res., 6: 1185-1189 (1993).

18. Dubois, A.L. Polymer-layered silicate nanocomposites: Preparation, properties and uses of a new class of materials. Mater. Sci. Eng. 28: 1-63 (2000).

19. Fornes, T.D.; Hunter, D.L.; Paul, D.R. Effect of sodium montmorillonite source on nylon 6/ clay nanocompositos. Polymer 45: 2321-2331 (2004). 
20. Liu, L.M.; Qi, Z.N.; Zhu, X.G. Studies on nylon 6 clay nanocompósitos by melt-intercalation process. J. Appl. Polym Sci., 71: 1133-1138 (1999).

21. LeBaron PC, Wang Z, Pinnavaia TJ. Polymerlayered silicate nanocomposites: an overview. Appl Clay Sci.,15(1): 11-29 (1999).

22. Ray SS, Okamoto M. Polymer-layered silicate nanocomposite: a review from preparation to processing. Prog Polym Sci., 28(11): 1539641 (2003).

23. Belbachir M., Bensaoula A., Composition and Method for Catalysis using Bentonites, US Patent. 2003/0069446 A1 (2003).

24. Belbachir M., Bensaoula A., US. Patent. 2001/6,274,527 B1 (2001).

25. Akane Okada, Arimitsu Usuki. The chemistry of polymer-clay hybrids. Materials Science and Engineering: C3: 109-115 (1995).

26. R. Iwamoto, H. Murase., Journal of Polymer Science: Part B: Polymer Physics, 41: 17221729 (2003).

27. Jianxin Tang, Nongyue He, Libo Nie, Pengfeng Xiao, Hong Chen., Surface Science 550: 2634 (2004).
28. Xue Q.: Spectroscopy in the study of macromolecular structure (in Chinese). High Education Publishers, Beijing (1995).

29. Om Prakash, S. A. Iqbal and G. Jacob., Orient. J. Chem., 29(3), 1079-1084 (2013)

30. A. Kumar, U. S. Yadav and B. K. Rai., Orient. J. Chem., 29(3), 1209-1212 (2013)

31. Kalpana S. Katti, Debashis Sikdar, Dinesh R. Katti, Pijush Ghosh, Devendra Verma, Molecular interactions in intercalated organically modified clay and claypolycaprolactam nanocomposites: Experiments and modeling, Polymer 47: 403-414 (2006).

32. Theng B. K. G..: The chemistry of clay-organic reactions. Halsted Press, New York (1974).

33. Velde B.: Introduction to clay minerals: Chemistry, origins, uses, and environmental significance. Chapman and Hall, London (1992).

34. L. F. Cai, Z. Y. Lin, H. Qian, Dispersion of nano-silica in monomer casting nylon6 and its effect on the structure and properties of composites, Express Polymer Letters 4(7: 397-403 (2010). 